\title{
Drug-induced immune haemolytic anaemia caused by levofloxacin
}

\author{
Shashvat Sukhal ${ }^{1}$, MD, Shweta Gupta ${ }^{2}, \mathrm{MD}$
}

\begin{abstract}
Drug-induced immune haemolytic anaemia (DIIHA) is extremely rare. We herein report a case of lifethreatening DIIHA due to levofloxacin. This is the second case reported in the literature. A 51-year-old woman presented with complaints of fatigue after 4-5 days of levofloxacin therapy for a lung infection. At presentation, she was found to have haemolysis with a positive Coombs test and IgG autoantibodies. Levofloxacin was identified as the probable culprit, using the Naranjo adverse drug reaction probability scale. Upon discontinuation of the drug and initiation of steroids, the patient's haematological parameters stabilised. Diagnosis of DIIHA is made through a history of intake of levofloxacin, clinical and laboratory features of haemolysis and a positive Coombs test. An autoantibody screen is most commonly positive for warm antibodies (IgG type). It is essential for clinicians to recognise this rare complication caused by a commonly prescribed medication, discontinue the offending drug and initiate treatment.
\end{abstract}

Keywords: drug-induced immune haemolytic anaemia, haemolytic anaemia, levofloxacin

\section{INTRODUCTION}

Drug-induced immune haemolytic anaemia (DIIHA) is extremely rare. Drugs such as methyldopa, fludarabine and procainamide have traditionally been associated with autoimmune haemolytic anaemia (AIHA), and fluoroquinolones such as temefloxacin, pefloxacin and ciprofloxacin have been associated with severe haemolysis.(1) To our knowledge, this case report is the second case of levofloxacin-induced AIHA reported in the literature. ${ }^{(2)}$ We herein report levofloxacin-induced DIIHA in a 51-year-old woman. We opine that DIIHA is generally under-reported, and that clinicians must be aware of this rare but life-threatening adverse reaction to a commonly prescribed drug.

\section{CASE REPORT}

A 51-year-old woman who had no significant past medical history presented at another hospital with productive cough and chest pain for the past 2-3 weeks. She was a known smoker who had consumed half a pack of cigarettes a day for 32 years. She was revealed to have bullous emphysema on chest radiography, but had normal blood counts. The patient had been afebrile with no viral prodrome. She was then empirically diagnosed with chronic obstructive pulmonary disease exacerbation and treated with a complete course of levofloxacin. She was subsequently referred to our hospital for further management of emphysema.

On presentation at our facility, apart from mild fatigue after 4-5 days of being on the antibiotic, a review of systems showed normalcy. She was found to be afebrile with normal vital signs. Physical examinations revealed pale conjunctivas and mucous membranes, along with mild icterus, but the rest of the systemic examination was normal. Initial laboratory tests showed severe anaemia (haemoglobin $5.4 \mathrm{~g} / \mathrm{dL}$, normal range 11.8-13.6 g/dL; mean corpuscular volume $125 \mathrm{fL}$, normal range 82-97 fL; white blood cell count $12,100 / \mu \mathrm{L}$; platelet count $334,000 / \mu \mathrm{L})$. She had a reticulocyte production index of 4.8 (reticulocyte count $30.2 \%$; haematocrit $24.2 \%$ ), with indirect hyperbilirubinaemia (total bilirubin $2.8 \mathrm{mg} / \mathrm{dL}$; direct bilirubin $0.5 \mathrm{mg} / \mathrm{dL}$ ) and an elevated lactate dehydrogenase level of $991 \mathrm{U} / \mathrm{L}$. A review of the peripheral blood smear revealed polychromasia, schistocytes and numerous nucleated red blood cells (RBCs). Haptoglobin level was undetectable and direct Coombs test was positive for IgG antibodies.

In view of the severe AIHA, the patient was started on immunosuppression with steroids - first dose of intravenous methylprednisolone $125 \mathrm{mg}$ and subsequent oral prednisone $80 \mathrm{mg} /$ day (weight-based dose $1 \mathrm{mg} / \mathrm{kg} /$ day). Additionally, 4 units of closely matched blood were transfused. She reported improvement after the blood transfusion and the initiation of steroids. The patient's haemoglobin levels stabilised to $10.8 \mathrm{~g} / \mathrm{dL}$ and her symptoms improved. The medication review showed that the only new drug prescribed to her in the past few weeks was levofloxacin for the empirical treatment of a lung infection.

The patient had no further haemolytic episodes. Prednisone was prescribed in full dose for one week and tapered over the next two weeks. The patient was doing well at the follow-up four months later. An immunological workup was also negative. Using the Naranjo adverse drug reaction probability scale, ${ }^{(3)}$ the patient's diagnosis was confirmed as haemolytic anaemia, possibly caused by levofloxacin (Table I).

\section{DISCUSSION}

Immune haemolytic anaemia is a clinical condition in which IgG and/or IgM antibodies bind to RBC surface antigens to initiate RBC destruction via the complement and reticuloendothelial systems.

${ }^{1}$ Department of Medicine, ${ }^{2}$ Division of Hematology \& Oncology, John H Stroger Jr Hospital of Cook County, Chicago, IL, USA

Correspondence: Dr Shashvat Sukhal, Fellow Physician, Division of Pulmonary, Critical Care and Sleep Medicine, John H Stroger Jr Hospital of Cook County, 1969 W Ogden Ave, Chicago, Illinois 60612, USA. ssukhal@cookcountyhhs.org 
Table I. Questionnaire based on the Naranjo adverse drug reaction probability scale. ${ }^{(3)}$

\begin{tabular}{|c|c|c|c|c|}
\hline Question & Yes & No & $\begin{array}{l}\text { Do not } \\
\text { know }\end{array}$ & Score* \\
\hline $\begin{array}{l}\text { 1. Are there previous conclusive reports } \\
\text { on this reaction? }\end{array}$ & +1 & 0 & 0 & +1 \\
\hline $\begin{array}{l}\text { 2. Did the adverse event occur after the } \\
\text { suspected drug was administered? }\end{array}$ & +2 & -1 & 0 & +2 \\
\hline $\begin{array}{l}\text { 3. Did the adverse reaction improve } \\
\text { when the drug was discontinued } \\
\text { or a specific antagonist was } \\
\text { administered? }\end{array}$ & +1 & 0 & 0 & +1 \\
\hline $\begin{array}{l}\text { 4. Did the adverse reaction reappear } \\
\text { when the drug was re-administered? }\end{array}$ & +2 & -1 & 0 & 0 \\
\hline $\begin{array}{l}\text { 5. Are there alternative causes (other } \\
\text { than the drug) that could have on } \\
\text { their own caused the reaction? }\end{array}$ & -1 & +2 & 0 & +2 \\
\hline $\begin{array}{l}\text { 6. Did the reaction reappear when a } \\
\text { placebo was given? }\end{array}$ & -1 & +1 & 0 & 0 \\
\hline $\begin{array}{l}\text { 7. Was the drug detected in } \\
\text { the blood (or other fluids) in } \\
\text { concentrations known to be toxic? }\end{array}$ & +1 & 0 & 0 & 0 \\
\hline $\begin{array}{l}\text { 8. Was the reaction more severe } \\
\text { when the dose was increased or } \\
\text { less severe when the dose was } \\
\text { decreased? }\end{array}$ & +1 & 0 & 0 & 0 \\
\hline $\begin{array}{l}\text { 9. Did the patient have a similar } \\
\text { reaction to the same or similar drugs } \\
\text { in any previous exposure? }\end{array}$ & +1 & 0 & 0 & 0 \\
\hline $\begin{array}{l}\text { 10. Was the adverse event confirmed } \\
\text { by any objective evidence? }\end{array}$ & +1 & 0 & 0 & +1 \\
\hline
\end{tabular}

The condition is classified into either autoimmune, alloimmune or drug-induced, depending on the antigenic stimulus responsible for the immune response. ${ }^{(1)}$

DIIHA is a rare condition. Although there is no good incidence data, according to rough estimates by experts in the field, the incidence is around one in every one million population. ${ }^{(1)}$ Around 130 drugs have been implicated, with three predominant groups of drugs: antimicrobials (42\%); anti-inflammatory (15\%); and antineoplastic (11\%). ${ }^{(1)}$ A suggested mechanism for DIIHA is the production of drug-independent antibodies, which can be detected in vitro without the addition of any drug, similar to RBC autoantibodies. Classically, methyldopa and fludarabine are the most common drugs to induce autoantibody formation. A second suggested mechanism for DIIHA is drug-dependent antibodies that will react in vitro only in the presence of the drug. These are likely combinations of drug-drug metabolite plus RBC membrane proteins. An example of this would be haemolysis caused by penicillin or cefotetan. ${ }^{(1,4,5)}$ Another mechanism is nonimmunologic protein adsorption, which has recently been postulated to decrease RBC survival time in patients taking drugs containing $\beta$-lactamase inhibitors. ${ }^{(1,6)}$

Our reported case satisfied the diagnostic criteria for AIHA, as it met the clinical and serological criteria of haemolysis (indirect hyperbilirubinaemia, decreasing haemoglobin level, elevated lactate dehydrogenase level, low haptoglobin level, and peripheral blood smear consistent with haemolysis) along with a positive Coombs test and an autoantibody screen showing IgG autoantibodies (warm antibodies). ${ }^{(4)}$ This was likely due to the induction of drug-independent antibodies (which are indistinguishable from RBC autoantibodies in AIHA) by levofloxacin.

The mainstay of treatment for warm antibody haemolysis is immunosuppression, with glucocorticoids such as oral prednisone (1-2 $\mathrm{mg} / \mathrm{kg} /$ day orally) as first-line therapy. The recommended duration of therapy is $1-3$ weeks, but low-dose maintenance therapy may be required for about half of such cases. Response is usually rapid and significant improvement in haematological parameters can be seen within a few days. ${ }^{(7)}$ Intravenous steroid therapy can be used to achieve faster responses in cases of severe haemolysis. For those who do not respond to steroids, other more potent immunosuppressants such as cyclophosphamide and azathioprine, in combination with high-dose steroids or surgical interventions such as splenectomy, can be considered. Cyclosporine, danazol, rituximab or intravenous immunoglobulin may be indicated in refractory cases. ${ }^{(4,7,8)}$

To our knowledge, only one other case of AIHA due to levofloxacin has been described in the literature - an 82-yearold man who had received $500 \mathrm{mg}$ /day of levofloxacin for cellulitis, as reported by $\mathrm{Oh}$ et al. ${ }^{(2)}$ In this patient, drug-induced autoantibody-mediated RBC destruction with a positive Coombs test and the presence of IgG antibodies (warm antibodies) were found. The patient also responded to withdrawal of levofloxacin and initiation of steroids. From the published literature and postmarketing surveillance studies, fluoroquinolones, temefloxacin, pefloxacin and ciprofloxacin have been associated with severe drug-induced haemolysis, sometimes with multiorgan failure (for which temefloxacin was withdrawn from the market in 1992). ${ }^{(9)}$ Although levofloxacin has been associated with tendinitis, acute hepatitis, cholestatic jaundice, thrombocytopenia and torsades de pointes, ${ }^{(9)}$ AlHA is exceedingly rare, ${ }^{(2)}$ with ours being the second case reported so far.

We opine that drug-induced antibody production is underestimated and under-reported, as many cases of DIIHA may not lead to dramatic haemolysis that commands attention. ${ }^{(5)}$ With ever increasing antibiotic use and increased reliance on newer generations of fluoroquinolones such as levofloxacin, such rare but life-threatening adverse reactions may be more frequently encountered. It is, therefore, essential for clinicians to recognise this rare complication caused by a commonly prescribed medication and be aware of its risks and management.

\section{REFERENCES}

1. Garratty G. Drug-induced immune hemolytic anemia. Hematology Am Soc Hematol Educ Program 2009:73-9.

2. Oh YR, Carr-Lopez SM, Probasco JM, Crawley PG. Levofloxacininduced autoimmune hemolytic anemia. Ann Pharmacother 2003; 37:1010-3. 
3. Naranjo CA, Busto $U$, Sellers EM, et al. A method of estimating the probability of adverse drug reactions. Clin Pharmacol Ther 1981; 30:239-45.

4. Gehrs BC, Friedberg RC. Autoimmune hemolytic anemia. Am J Hematol 2002; 69:258-71.

5. Garratty G. Immune hemolytic anemia caused by drugs. Expert Opin Drug Saf 2012; 11:635-42.

6. Broadberry RE, Farren TW, Bevin SV, et al. Tazobactam-induced haemolytic anaemia, possible cause by non-immunological adsorption of IgG onto patient's red cells. Transfus Med 2004; 14:53-7.

7. Petz LD. Treatment of autoimmune hemolytic anemias. Curr Opin Hematol 2001; 8:411-6.

8. Winklestein A, Kiss JE. Immunohematologic disorders. JAMA 1997; 278:1982-92.

9. Campi P, Pichler WJ. Quinolone hypersensitivity. Curr Opin Allergy Clin Immunol 2003; 3:275-81. 